\title{
Rheumatoid Arthritis Synovial Membrane Contains a 62,000-Molecular-Weight Protein That Shares an Antigenic Epitope with the Epstein-Barr Virus-encoded Associated Nuclear Antigen
}

\author{
Robert Fox, Richard Sportsman, Gary Rhodes, Janos Luka*, Gary Pearson*, and John Vaughan \\ Department of Basic and Clinical Research, Scripps Clinic and Research Foundation, La Jolla, California 92037; \\ and ${ }^{*}$ Department of Microbiology, Georgetown University, Washington, District of Columbia 20037
}

\begin{abstract}
A monoclonal antibody, selected for reactivity with the EpsteinBarr virus (EBV)-encoded antigen EBNA-1, exhibited strong reactivity with the synovial lining cells in joint biopsies from 10 of 12 patients with rheumatoid arthritis (RA) and adherent cells eluted from these tissues. No staining of RA synovial membrane frozen tissue sections or eluted synovial-lining cells was obtained with monoclonal antibodies directed against other EBV-encoded antigens (anti-p160, anti-gp200/350) or with monoclonal antibodies directed against antigens encoded by cytomegalovirus, herpes simplex viruses, or human $\mathbf{T}$ cell leukemia virus type $\mathbf{I}$. Among 12 osteoarthritis and normal synovial biopsies only rare reactive cells were noted.

Characterization of the antigen(s) in RA synovium by the Western immunoblotting technique revealed a 62,000-molecularweight (mol-wt) protein, in contrast to the 70,000-85,000-molwt EBNA-1 antigen found in EBV-transformed cells. The structural basis for the cross-reactivity of the RA synovial membrane 62,000-mol-wt protein and the EBNA-1 antigen appears to reside in the glycine-alanine rich region of these molecules. A rabbit antibody directed against a synthetic peptide (IR3-VI-2) derived from the glycine-alanine-rich region of EBNA-1 reacted with the 70,000-85,000-mol-wt EBNA-1 antigen in EBV-infected cells and with the 62,000-mol-wt molecule in RA synovial membrane extracts. Since strong antibody responses to EBNA-1 are known to exist in RA patients, these results suggest that immune responses to a cross-reactive antigen may play a role in the pathogenesis of RA.
\end{abstract}

\section{Introduction}

Several lines of evidence have indirectly implicated Epstein-Barr virus (EBV) ${ }^{1}$ in the etiology of rheumatoid arthritis (RA) (1).

This is publication No. 3977BCR from the Research Institute of Scripps Clinic.

Address reprint requests to Dr. Fox. Dr. Sportsman's current address is Department of Biochemistry, Eli Lilly Research Laboratories, Indianapolis, IN.

Received for publication 9 July 1985.

1. Abbreviations used in this paper: CMV, cytomegalovirus; DAB, $3^{\prime} 3^{\prime}$ diaminobenzidine; EBNA-1, nuclear antigen with 70,000-80,000 mol wt; EBV, Epstein-Barr virus; FCS, fetal calf serum; HSV-1 and HSV-2, herpes simplex virus types 1 and 2, respectively; HTLV-1, human Tleukemia virus type 1 ; IR-3, internal repeat region 3; MAb, monoclonal

J. Clin. Invest.

(C) The American Society for Clinical Investigation, Inc.

0021-9738/86/05/1539/09 \$1.00

Volume 77, May 1986, 1539-1547
EBV is a potent polyclonal B cell activator capable of inducing rheumatoid factor (anti-human IgG) synthesis (2). RA patients have higher titers of anti-EBV antibodies than age-matched controls (3-5), and peripheral blood lymphocytes from these patients have an increased proportion of circulating $B$ cells infected by EBV $(2,6)$, which is perhaps due to an abnormal response of their T cells to EBV infection $(7,8)$. Nevertheless, direct evidence for the involvement of EBV in the pathogenesis of RA is still lacking. A recent study by Alspaugh et al. (9) failed to find increased levels of EBV DNA within RA synovial membranes. However, low amounts of viral DNA would not be detected using these methods of hybridization. Therefore, we used monoclonal antibodies (MAbs) and immunohistologic techniques to determine whether RA synovial tissues contained cells that were infected with EBV or that contained antigens crossreactive with $\mathrm{EBV}$-encoded antigens.

Transformation of B lymphocytes by EBV leads to expression of a nuclear antigen with a molecular weight of 70,000-85,000 termed EBNA-1. The function of this DNA binding protein remains unknown, but recent studies have suggested that it may play a role in regulating viral and perhaps cellular DNA synthesis (10). An unusual feature of EBNA-1 is the presence of a long repetitive sequence of glycine and alanine that may extend to over 200 amino acids (11). This portion of the EBNA-1 molecules is encoded by the internal repeat region 3 (IR-3) of the EBV genome (12). Recently, Luka et al. (13) used EBNA-1 as an immunogen to produce an MAb (MAb P135) that reacted with an antigenic epitope encoded by the IR-3 region of EBV. Specifically, this antibody was able to immunoprecipitate the fusion protein of the glycine-alanine domain of EBNA- 1 and $\beta$-galactosidase (13). They also found that this MAb reacted with a 62,000 -mol-wt protein in lymphoblastoid cell lines lacking the EBV genome (13). The structural basis for this cross-reactivity probably resides in the presence of IR-3-like genes in normal human genomic DNA (12). The "cellular" 62,000-mol-wt protein differed from the EBNA-1 antigen in its peptide map and in its predominantly cytoplasmic location (13). Of importance, sera from patients with infectious mononucleosis produced antibodies against the 62,000 -mol-wt protein in parallel with antibodies against the EBNA-1 antigen, indicating the occurrence of a cross-reactive antigen in vivo. The relative amounts of this cellular antigen in normal tissues and its potential increases in expression associated with disease states remained unknown. While examining RA synovial membrane for the presence of EBV-associated antigens, we found a strong reactivity of the lining cells with MAb P135. Since RA patients exhibit strong

antibody; MAb P135, EBNA-1 immunogen that produces MAb; PAGE, polyacrylamide gel electrophoresis; PE-MAb-SC2, phycoerythrin-conjugated monoclonal anti-HLA-DR antibody; RA, rheumatoid arthritis; SLE, systemic lupus erythematosus. 
antibody responses against antigens encoded by the IR-3 region of EBV (5), immune responses against a cross-reactive protein in RA synovium could play a role in initiation or perpetuation of the disease process.

\section{Methods}

Patient population. Rheumatoid synovial tissue was obtained from 12 patients with definite or classic seropositive RA at the time of synovectomy or total joint replacement. Synovial membranes were obtained from 11 patients with osteoarthritis, 4 patients with non-RA synovitis (systemic lupus erythematosus [SLE], pigmentary villonodular synovitis, psoriasitic arthritis, and Reiter's syndrome) at the time of total joint replacement and from two immunologically normal individuals undergoing arthroscopic knee surgery for cartilage repair. The clinical and histologic features of these RA and non-RA synovial tissues has recently been presented (14). Titers of rheumatoid factor (anti-human IgG) and anti EBNA-1 antibodies were detected as previously described (5, 14, 15).

$M A b s$. MAbs against EBV-associated antigens that were used in this study are summarized in Table I. MAb P135 was prepared by immunizing murine splenocytes with purified EBNA-1 (13) and selected for reactivity with this antigen. As described above, it subsequently became apparent that MAb P135 was not specific for EBNA-1, since EBV genome-negative lymphoblastoid cell lines also expressed a cross-reacting 62,000-mol-wt antigen (13). We also used MAbs against other EBV-encoded antigens including the early restricted antigen (MAb R63), late structural protein p160 (MAb V3), viral membrane antigen glycoprotein (gp) 200/350 (MAb 2L10.1) (16-18), and against antigens encoded by other viruses including cytomegalovirus (CMV), herpes simplex virus type 1 (HSV-1), herpes simplex virus type 2 (HSV-2), and human T-leukemia virus type 1 (HTLV-1) (19-21) (Table I).

Antibody SC2 detects a nonpolymorphic determinant on histocompatibility antigen HLA-DR (15). Antibody Leu-CR3 (Becton-Dickenson \& Co., Oxnard, CA) reacts with the complement receptor CR3, which binds the complement fragment iC $3 \mathrm{~b}$. Complement CR3 receptors have previously been demonstrated to be present on RA synovial lining cells, monocytes, and other cells of hematopoietic origin (14, 22-24). Control murine hybridoma antibodies lacking anti-human activity included MOPC-21 (IgG 1-kappa) R1-1 (IgG 2-kappa), and F40 (IgM-kappa). Specific MAbs were used as a tissue culture supernatant $(5 \mu \mathrm{g} / \mathrm{ml})$ or as a dilution of immunoglobulin purified from ascites $(10-25 \mu \mathrm{g} / \mathrm{ml})$.

Antibodies produced against synthetic peptides derived from the DNA sequence of EBNA-1. To further characterize the antigen(s) in RA synovium, we used rabbit antibodies directed against synthetic peptides (IR3VI-0 and IR3-VI-2) (25) and immunoblotting methods. These synthetic peptides are from adjacent regions of the glycine-alanine-rich region of
EBNA-1 encoded by the IR-3 region of the EBV genome. Rabbits were immunized subcutaneously, with these synthetic peptides covalently linked to keyhole limpet-hemocyanin (KLH) using complete Freund's adjuvant. The specificity of this antipeptide antibody was demonstrated by the ability of the specific peptide to block antibody reactivity with EBNA-1. The synthetic peptide did not react with MAb P135 or block its binding to EBNA-1 antigen (unpublished observations). In contrast to MAb P135, the rabbit anti-synthetic peptide antibodies did not react with acetone-fixed cells in immunohistologic assays. Thus, antisynthetic peptide antibodies and MAb P135 detect distinct antigenic epitopes of the EBNA-1 molecule.

Tissue culture of lymphoblastoid cell lines and synovial membrane cells. EBV-transformed lymphoblastoid B cell lines were grown in medium RPMI 1640 containing $100 \mu \mathrm{g} / \mathrm{ml}$ streptomycin, $10 \mathrm{mM}$ glutamine, and $10 \%$ fetal calf serum (FCS) (Gibco, Grand Island, NY). As a source of infectious EBV, we induced P3HR-1 cells using phorbol myristic acetate as previously described (18). Synovial-lining cells of RA synovial membrane were prepared by collagenase digestion for $2 \mathrm{~h}$, rinsing the eluted cells, and growth of the adherent cells on glass slides (multichamber slides, Lab Tek, Ames Co., Elkhart, IN) at $37^{\circ} \mathrm{C}$ in medium RPMI 1640 plus $10 \%$ FCS.

Immunohistologic staining of cell suspension and frozen tissue sections. Fresh surgical samples of synovial membrane or other tissues were cut into $0.5 \times 0.5-\mathrm{cm}$ blocks and placed in airtight plastic capsules containing OCT mounting compound (14) before freezing in isopentane/ dry ice bath and storage at $-70^{\circ} \mathrm{C}$. Frozen tissue sections $(5 \mu \mathrm{m}$ in thickness) or slides containing tissue culture chambers were fixed in cold acetone, rinsed twice in PBS containing 5\% normal goat serum, and reacted with specific MAbs or with a control myeloma protein of the same isotype and concentration. After rinsing, the bound MAb were visualized with biotin-conjugated goat anti-mouse Ig (Tago, Burlingame, CA), followed by avidin-conjugated horseradish peroxidase (Tago), and substrate 3'3' diaminobenzidine (DAB) (Sigma Chemical Co., St. Louis, MO) (14). The slides were counterstained with methylene blue and read in a blinded manner. For two-color immunofluorescent staining, MAb P135 and fluorescent-conjugated anti-mouse IgM were followed by phycoerythrin-conjugated monoclonal anti-HLA-DR antibody (PEMAb-SC2).

Preparation of tissue extracts and immunoblotting. Fresh surgical biopsies of synovial membrane tissue from RA patients (four patients), osteoarthritis synovial membranes (three patients), or normal tonsillar lymph node (three patients) were cut in $1 \times 1-\mathrm{cm}$ blocks, frozen in liquid nitrogen, and fragmented into small pieces with a hammer. The resulting powder was solubilized with $0.5 \%$ NP40 (Shell Oil Co., Houston, TX), $0.4 \mathrm{M} \mathrm{NaCl}, 20 \mathrm{mM}$ Tris/ $\mathrm{HCl}$ (pH 7.4) containing $1 \mathrm{mM}$ phenylmethylsulfonyl fluoride. The extracts were then centrifuged at $40,000 \mathrm{~g}$ for $\mathbf{4 5} \mathrm{min}$. The protein content of the supernatant was determined by the

Table I. Monoclonal Anti-viral Antibodies

\begin{tabular}{|c|c|c|c|c|}
\hline Antibody & Isotype & Antigen detected & $\begin{array}{l}\text { Molecular weight } \\
\text { of antigen }\end{array}$ & Reference \\
\hline \multicolumn{5}{|c|}{ Antibodies against EBV-associated antigens } \\
\hline P135 & IgM & EBNA-1 & $70,000-85,000^{*}$ & (13) \\
\hline $2 \mathrm{~L} 10.1$ & IgG 2 & Membrane antigen & gp 200/350 & $(16)$ \\
\hline V3 & IgG 2 & Capsid antigen & 160 & (17) \\
\hline $\mathbf{R 6 3}$ & IgG 2 & EA-R & 85 & (18) \\
\hline \multicolumn{5}{|c|}{ Antibodies against other viral-associated antigens } \\
\hline CMV-C5 & IgG 2 & Late cytoplasmic protein & 80 & (19) \\
\hline HSV-1-G11 & IgG 2 & gp-c & 120 & (20) \\
\hline HSV-II-A6 & IgG 2 & Early antigen & 140 & (20) \\
\hline HuTLV-1 & & p19 & 19 & $(21)$ \\
\hline
\end{tabular}

* Molecular weight of EBNA-1 is 70,000-85,000. A 62,000-mol-wt molecule reactive with this MAb can also be detected in EBV genome-negative cells (13). 
Lowry method and amido black staining of dot blots followed by laser densitometry as previously described (26).

Samples containing $50 \mu \mathrm{l}$ of tissue extract (containing $1-10 \mathrm{mg} / \mathrm{ml}$ protein content) were electrophoresed under reducing conditions with $0.1 \%$ sodium dodecyl sulfate (SDS) on $8 \%$ polyacrylamide gels and the gels were electrophoretically transferred to nitrocellulose paper (26). Nonspecific binding to the nitrocellulose paper was then blocked by incubation for $15 \mathrm{~min}$ in blotto, a powdered milk-based reagent (27). MAb P135 or control murine myeloma protein was reacted at room temperature for $1 \mathrm{~h}$, and followed by rabbit anti-mouse $\mathrm{Ig}$ at pretitered dilutions in blotto. Presence of MAb P135 reactive material was assessed by reacting the paper strips with peroxidase-conjugated goat anti-rabbit Ig (Tago) followed by 0.05\% 4-chloro-1-naphthol (4CN) (Sigma Chemical Co.) in $0.05 \mathrm{M}$ sodium acetate buffer, $\mathrm{pH} 5.8$, containing $0.05 \% \mathrm{H}_{2} \mathrm{O}_{2}$. Reactivity with rabbit anti-synthetic peptide antibody was detected by binding of ${ }^{125}$ I-labeled staphylococcal protein A (Calbiochem-Behring Corp., San Diego, CA).

\section{Results}

Reactivity of $R A$ synovial membrane tissues with MAb. To detect cells in RA synovial membrane containing EBV-encoded gene products or cellular antigens cross-reactive with EBV-encoded antigens, frozen tissue sections of biopsy specimens were stained with MAbs using an immunoperoxidase technique. The synovial-lining cells from RA patients showed cytoplasmic staining with MAb P135 (Fig. $1 A$ ), where positive reaction is indicated by dark cytoplasmic staining (arrows in $A$ ). The subsynovial lymphocytes were not reactive, although their nuclei have been counterstained with methylene blue. As a control, prior absorption of the MAb P135 with extracts of EBV-transformed cells eliminated this reactivity $(E)$. Staining of $40-75 \%$ of synovial lining cells by MAb P135 (mean, 56 $\pm 18 \%$ ) was found in 10 of 12 RA synovial membranes. A weaker degree of staining (Fig. $1 C$ ) with $2-10 \%$ reactive cells (median, $7 \pm 3 \%$ ) was found in the remaining two RA synovial membranes. These results are summarized in Table II. The reaction of RA synovial membranes with MAb P135 was not related to the patient's age, disease duration, or rheumatoid factor titer (Table II). No significant staining of a serial section of RA synovium was obtained with a control IgM myeloma protein (a lower power photomicrograph is shown in Fig. $1 B$ ). Also, the synovial sections were not reactive with other anti-EBV MAbs, including MAb 2L10.1 (anti-gp200/ 350), MAb V3 (anti-p160), or MAb R63 (anti-EA-R) (data not shown).

In agreement with prior studies by others (28-30) and by our laboratory (14), we found that the majority of synoviallining cells from RA biopsies expressed intense staining with antibodies directed against HLA-DR antigen (Fig. $1 D$ and Table II) and complement receptor CR3 (Fig. $1 F$ ). Analysis of serial tissue sections of RA and two-color immunofluorescence studies demonstrated that synovial-lining cells reactive with MAb P135 also reacted with anti-HLA-DR and anti-CR3 antibodies.

Reactivity of $R A$ synovial-lining cells obtained by collagenase digestion with MAb P135. RA synovial-lining cells, isolated by brief collagenase treatment of synovial membrane biopsies and cultured in vitro for $48 \mathrm{~h}$, exhibited cytoplasmic staining with MAb P135 (Fig. $2 A$ ) but neither with antibody 2L10.1 (antigp200/350) (Fig. 2 B), anti-EA-D, nor anti-EA-R antibodies (data not shown). Thus, markers found in situ on frozen tissue sections were also present on isolated synovial-lining cells after $48 \mathrm{~h}$ in culture.

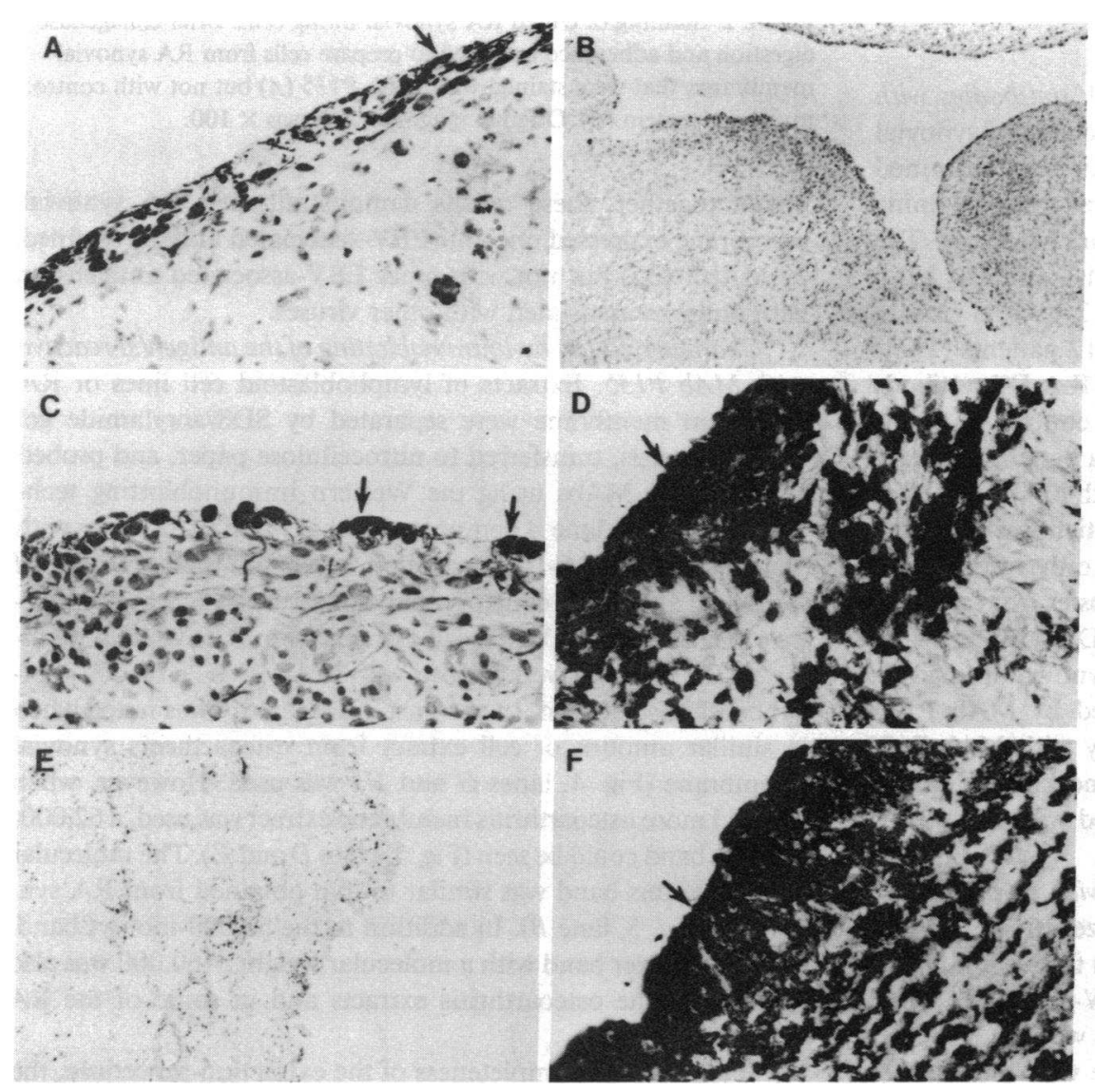

Figure 1. Immunohistologic detection of antigens in RA synovial membrane reactive with MAbs. Frozen tissue sections of RA synovial membrane were stained with specific MAb or control myeloma protein, biotin-conjugated anti-mouse Ig, avidin-conjugated horseradish peroxidase, substrate DAB, and methylene blue counter stain. $(A)$ Positively stained cells with MAb P135 (anti-EBNA-1) exhibit a dark color (arrows). (B) A serial section of RA synovial membrane was stained with control myeloma IgM protein lacking anti-human activity and no specific staining was present. $(C)$ RA synovial membrane from a different patient that exhibited a pattern of staining with fewer cells reactive with MAb P135. ( $D$ and $F$ ) RA synovial membrane (from the same patient as in $A$ and $B$ ) stained with anti-HLA-DR MAb $(D)$ and anticomplement receptor CR3 antibody (Leu CR3) $(F)$. Original magnification in $B$ was $\times 40$ and in the other frames was $\times 100$. $(E)$ MAb P135 was preincubated with an extract of EBV-transformed B cells before staining an RA synovial membrane. 
Table II. Immunohistologic Characterization of Synovial and Other Tissue Biopsies Using MAbs

\begin{tabular}{|c|c|c|c|c|c|}
\hline & \multicolumn{3}{|l|}{ MAb } & \multirow[b]{2}{*}{$\begin{array}{l}\text { RF } \\
\text { (titer) }\end{array}$} & \multirow[b]{2}{*}{$\begin{array}{l}\text { Disease } \\
\text { duration }\end{array}$} \\
\hline & P135* & $\begin{array}{l}\text { Anti- } \\
\text { HLA-DR* }\end{array}$ & $\begin{array}{l}\text { Anti- } \\
\text { C3bR }\end{array}$ & & \\
\hline & & & & & $y r$ \\
\hline \multicolumn{6}{|l|}{ RA } \\
\hline Cases 1-8 & +++ & +++ & ++ & 5,280 & $7.5 \pm 2.9$ \\
\hline Cases 9-11 & + & +++ & ++ & 2,640 & $6.9 \pm 3.2$ \\
\hline \multicolumn{6}{|l|}{ Osteoarthritis } \\
\hline Cases $1-5$ & + & + & + & $<10$ & $14.2 \pm 4.9$ \\
\hline Cases 6-11 & - & + & + & $<10$ & $12.1 \pm 5.2$ \\
\hline \multicolumn{6}{|l|}{$\begin{array}{l}\text { Non-RA } \\
\text { synovitis }\end{array}$} \\
\hline Psoriatic & ++ & ++ & + & $<10$ & 6 \\
\hline SLE & - & ++ & + & $<10$ & 3 \\
\hline $\begin{array}{c}\text { Villonodular } \\
\text { synovitis }\end{array}$ & - & ++ & + & $<10$ & 1 \\
\hline Reiter's & & & & & \\
\hline syndrome & + & ++ & + & $<10$ & 1 \\
\hline Normal tissues & & & & & \\
\hline $\begin{array}{l}\text { Liver, muscle, } \\
\text { and brain }\end{array}$ & - & - & - & $<10$ & - \\
\hline Lymph node & & & & & \\
\hline and spleen & - & + & + & $<10$ & - \\
\hline
\end{tabular}

* Staining with MAbs was evaluated ++++ for $>75 \%$ of reactive cells; +++ for $40-75 \%$ of synovial-lining cells stained; ++ for $10-40 \%$ reactive cells; + for $2-10 \%$ reactive synovial-lining cells; and - for $<2 \%$ of cells stained.

Lack of reactivity of monoclonal anti-EBV antibodies with tissue from non-RA patients. Frozen tissue sections of synovial membranes from 12 patients with osteoarthritis were examined with monoclonal anti-EBV antibodies. Scattered synovial-lining cells were reactive with MAb P135 (arrow in Fig. 3 A). The proportion of osteoarthritis synovial-lining cells stained by MAb P135 in osteoarthritis patients ranged from 2 to $10 \%$ (mean, $4 \pm 35 \%$ ) in 7 of 12 patients and $<2 \%$ in 5 of 12 patients (Table II). Scattered cells were also stained with anti-HLA-DR antibody (Fig. $3 C$ ), but no staining was noted with control myeloma protein (Fig. $3 \mathrm{~B}$ ). In a synovial biopsy from a patient with psoriatic arthritis, synovial-lining cells reactive with MAb P135 were present (Fig. $3 D$ ). In synovial biopsies from patients with Reiter's syndrome, SLE, and villonodular synovitis, only rare reactive cells were stained (Table II). These latter biopsies from non-RA patients exhibited staining with anti-HLA-DR and anti-CR3 antibodies (Table II), indicating that some synovial-lining cells express these antigens without being stained by MAb P135. Normal tissues were examined for reactivity with MAb P135 included liver, spleen, lymph node, brain, and kidney. No significant staining of these tissues was obtained with MAb P135 (Table II).

Lack of reactivity of synovial membranes with MAbs to CMV, $H S V$, or HTLV-1-associated antigens. Frozen tissue sections from RA synovial membrane were examined for reactivity with MAbs directed against CMV, HSV-1, HSV-2, and HTLV-1 (Table I). All 12 RA synovial membranes, as well as all osteoarthritis synovial membranes, were unreactive with these MAbs.

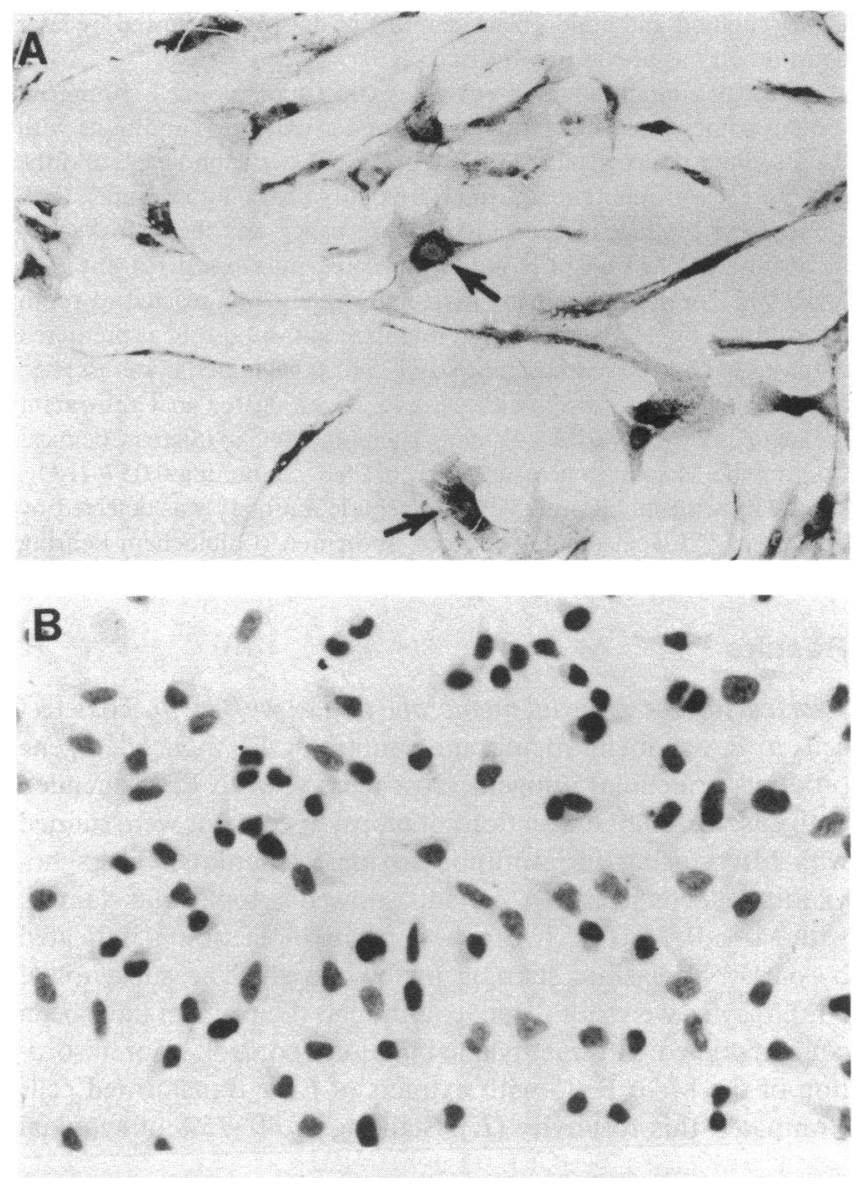

Figure 2. Staining of eluted RA synovial-lining cells. Brief collagenase digestion and adherence was used to prepare cells from RA synovial membranes that were stained with MAb P135 $(A)$ but not with control myeloma protein $(B)$. Original magnification was $\times 100$.

Taken together, these results demonstrate that RA synovial membrane expressed one anti-EBV-associated antigen (defined by MAb P135) but not with other EBV-associated antigens or with antigens associated with other viruses.

Characterization by immunoblotting of the antigen(s) reactive with MAb P135. Extracts of lymphoblastoid cell lines or RA synovium membrane were separated by SDS/acrylamide gel electrophoresis, transferred to nitrocellulose paper, and probed with various MAbs using the Western immunoblotting technique. In Fig. 4, lane $A$ demonstrates that MAb P135 reacts with the purified EBNA-1 antigen that has a molecular weight of 75,000 (13), while a control monoclonal antibody was nonreactive (Fig. 4, lane $B$ ). When cell extracts from RA synovial membrane (lanes $C-F$ ) were probed with MAb P135, a 62,000-molwt band was detected. In contrast, no reactivity was noted when a similar amount of cell extract from osteoarthritis synovial membrane (Fig. 4, lanes $G$ and $H$ ) was used. However, when 10-fold more osteoarthritis membrane extract was used, a 62,000mol-wt band could be seen (Fig. 5, lanes $D$ and $E$ ). The molecular weight of this band was similar to that obtained from RA synovium (Fig. 5, lane $B$ ). In addition to the 62,000 -mol-wt band, a slightly lower band with a molecular weight $\sim 60,000$ was also present in the osteoarthritis extracts and in some of the RA extracts.

To assess the completeness of the extraction procedure, the 


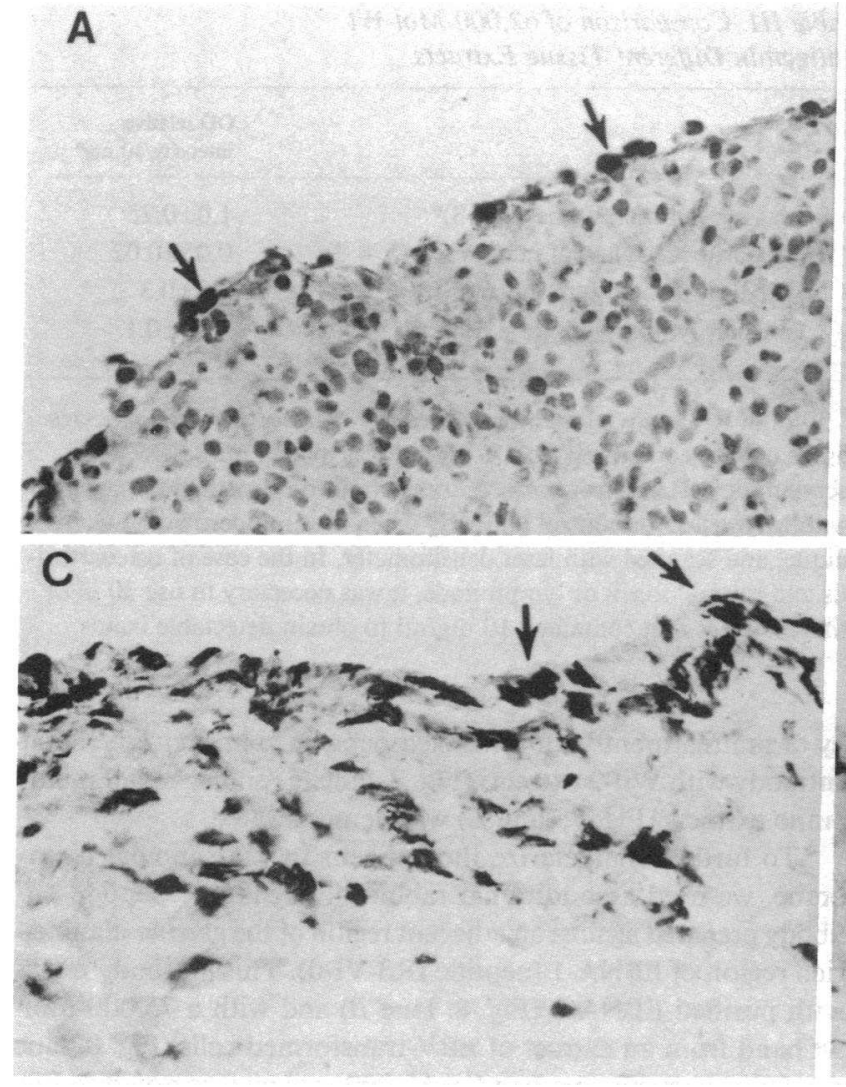

Figure 3. Immunohistologic evaluation of synovial membrane from non-RA patients. Frozen tissue sections from synovial membrane were obtained at time of surgery from osteoarthritis patients lacking autoimmune disease. In each case, the tissue sections were stained as described in the legend to Fig. 1 using MAb P135 $(A)$, control my-

cellular pellet obtained after NP40 detergent extraction of synovial membrane was partially solubilized by boiling in SDSmercaptoethanol polyacrylamide gel electrophoresis (PAGE) buffer and analyzed by Western blotting. No reactivity with MAb P135 was noted with the pellet from RA synovial membrane (Fig. 5, lane $C$ ) or from osteoarthritis membrane (data not

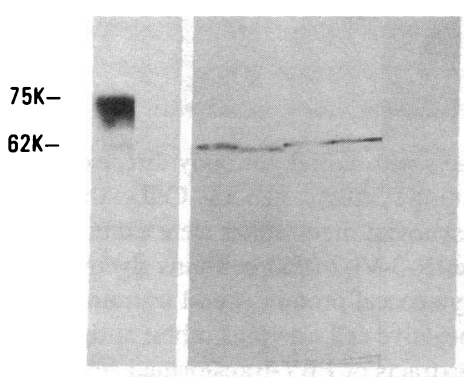

Figure 4. Immunoblotting of cell extracts using MAb P135. Cell extracts from EBV transformed cells or human tissues were applied to $10 \%$ SDS acrylamide gels, electrophoresed, and transferred to nitrocellulose paper. The strips of nitrocellulose paper were exposed to either MAb P135 tissue culture supernatant or control myeloma protein

$(5 \mu \mathrm{g} / \mathrm{ml})$, goat anti-mouse Ig, peroxidase coupled swine anti-goat Ig, and substrate $4 \mathrm{CN}$. Lane $A$ : EBNA-1 antigen purified from the EBV transformed lymphoblastoid Raji cells plus MAb P135. Lane $B$ : EBNA-1 antigen (same as lane $A$ ) with control myeloma protein. Lanes $C$ to $F$ : Cell extracts from RA synovial membrane plus MAb P135. Lanes $G$ and $H$ : Cell extracts from osteoarthritis synovial membranes plus MAb P135.
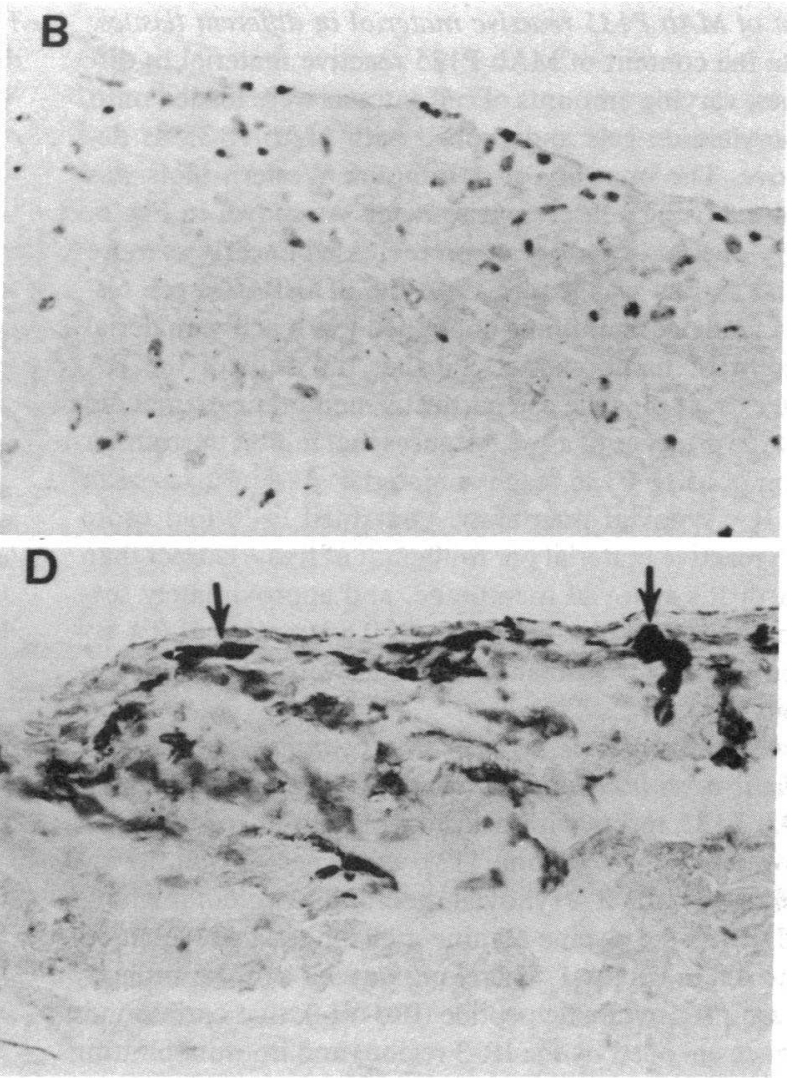

eloma protein $(B)$, and anti-HLA-DR antibody $(C)$. In $D$, a psoriatic arthritis synovial membrane stained with MAb P135. The arrows in $A$, $C$, and $D$ indicate positively stained cells that have a brown color and can be distinguished from the blue color of the methylene blue counterstain.

shown). These results suggest that osteoarthritis synovial membrane contains a 62,000 -mol-wt protein similar in molecular weight to the antigen found in RA synovial membrane. However, the concentration of this antigen in osteoarthritis synovial membrane extracts was lower than in RA membrane, and the decreased amounts of this antigen in osteoarthritis membrane could not be attributed to the extraction procedure.

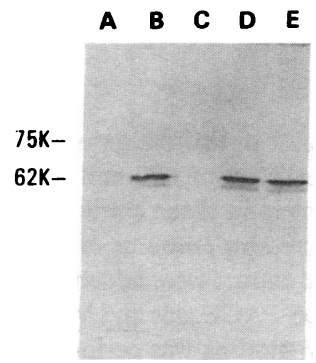

Figure 5. Extraction of the cellular 62,000 -mol-wt antigen from synovial tissues. Cellular extracts of RA or osteoarthritis synovial membrane were prepared using NP40 detergent as described in the Methods section. The supernatants from these detergent extracts were loaded onto $10 \%$ SDS gels and analyzed by Western immunoblotting as described above in lanes $A, B, D$, and $E$. In lane $C$, the pellet from the initial NP40 extraction was partially solubilized by boiling in SDS-mercaptoethanol PAGE buffer and analyzed by immunoblotting. Lanes $A$ and $B$ : Tissue extract from an RA synovial membrane $(1 \mathrm{mg} / \mathrm{ml})$ was treated with a control myeloma protein (lane $A$ ) or MAb P135 (lane $B$ ). Lane $C$ : The "pellet" from osteoarthritis synovial membrane was partially solubilized as described above and the extract $(15 \mathrm{mg} / \mathrm{ml})$ was reacted with MAb P135. Lanes $D$ and $E$ : Extracts of osteoarthritis synovial membranes $(15 \mathrm{mg} /$ $\mathrm{ml}$ ) were reacted with MAb P135. 
Content of MAb P135 reactive material in different tissues. To estimate the content of MAb P135 reactive material in different tissues, varying amounts of cell extracts were loaded onto SDS/polyacrylamide gels and probed with MAb P135 as described above. The intensity of staining on Western blots was then examined using a laser densitometer. As shown in Fig. 6, the intensity of colorimetric reaction increased linearly as more RA synovial extract was loaded onto the SDS/PAGE gel. Osteoarthritis synovial membrane contained less reactive material per milligram of tissue extract. Further, mixture of the RA membrane extract plus the osteoarthritis membrane extract did not suggest the presence of any substances that inhibit the transfer or detection of MAb P135 reactive material. As summarized in Table III, RA synovial membrane contained $\sim 20$-fold more MAb P135 reactive material per milligram of tissue extract than did osteoarthritis synovial membrane, and approximately sevenfold more than tonsillar lymph node. The content of RA synovial membranes was similar to that in EBV-transformed lymphoblastoid cell.

$R A$ synovial membrane extracts contain antigens in common with synthetic peptides derived from the IR-3 region of $E B N A-1$. Since MAb P135 reacts with a fusion protein encoded by the IR-3 region of the EBV genome (13), we suspected that the antigenic epitope on the RA synovial membrane protein might be contained within the glycine-alanine-rich amino acid sequences that are present in EBNA-1. Therefore, we used a rabbit antibody prepared against a synthetic peptide (IR3-VI-0, that corresponds to a sequence encoded by the IR-3 region) and immunoblotting to evaluate cell and tissue extracts. As in Fig. 7 (lane $B$ ), extracts of an EBV-transformed cell line (Wil-2) contain a band of 77,000mol-wt, similar to the previously reported molecular weight of EBNA-1 in this cell line (31). In addition, a band at 62,000 can be noted. In lane $C$ (Fig. 7), extracts from a different EBV-transformed cell line contained a 72,000-mol-wt band as well as a band at $62,000 \mathrm{~mol} w t$. Studies of extracts from additional EBVtransformed cell lines (i.e., Raji, Daudi, and P3HR-1) have demonstrated a higher molecular weight band, ranging from $65,000-80,000$ mol wt (corresponding to the known molecular weight of EBNA-1 in each cell line) plus an additional 62,000mol-wt band (unpublished observations). Extracts from an EBVnegative cell line (BJAB) (Fig. 7, lane $A$ ) and from RA synovial membranes (Fig. 7, lanes $D-F$ ) contained bands with a molecular weight of $\sim 62,000$. In contrast, normal and osteoarthritis synovial membranes (Fig. 7, lanes $G-J$ ) did not contain sufficient 62,000-mol-wt antigen to be detected by this antibody. The abil-

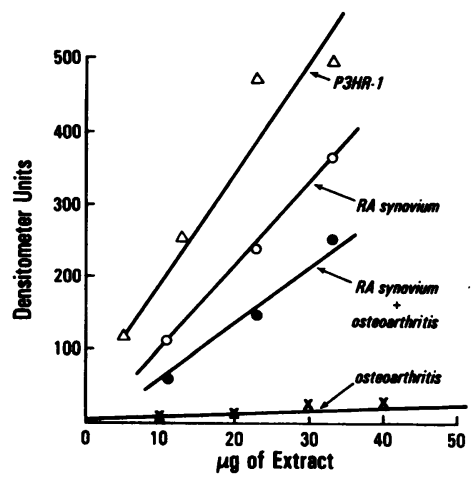

Figure 6. Estimation of the content of 62,000-mol-wt protein in tissue extracts. Increasing amounts of tissue extract were added to SDS-PAGE gels and Western blotting was performed as described above. $\mathrm{A}$ laser densitometer was used to estimate the amount of MAb $P 135$ reactive material in the band from 55,000 to $65,000 \mathrm{~mol}$ wt. In some experiments, RA synovial extracts were added to osteoarthritis extracts before electrophoresis.
Table III. Comparison of 62,000-Mol-Wt Antigen in Different Tissue Extracts

\begin{tabular}{ll}
\hline Tissue & $\begin{array}{l}\text { OD relative } \\
\text { intensity } / 10 \mathrm{mg}^{*}\end{array}$ \\
\hline RA synovial membrane $(n=3)^{*}$ & $1.0 \pm 0.25$ \\
Osteoarthritis synovial membrane $(n=3)$ & $0.05 \pm 0.02$ \\
EBV-transformed lymphocytes $(n=3)$ & $1.3 \pm 0.3$ \\
Tonsillar lymph node $(n=3)$ & $0.15 \pm 0.1$ \\
\hline
\end{tabular}

* $30 \mu \mathrm{l}$ of RA synovial membrane or EBV-transformed lymphocytes tissue extract containing from $1 \mathrm{mg} / \mathrm{ml}$ was loaded onto SDS/polyacrylamide gels, electrophoresed, transferred to nitrocellulose, reacted with MAb P135 or control antibody using immunoperoxidase technique, and scanned with laser densitometer. In the case of osteoarthritis and normal tonsil or lymph node, it was necessary to use $30 \mu l$ of tissue extract that contained $10 \mathrm{mg} / \mathrm{ml}$ to obtain detectable bands.

ity of pretreatment with unlabeled peptide to inhibit this rabbit antibody with Wil-2 extracts (Fig. 7, lane $K$ ) and synovial membrane extracts (Fig. 7, lane $L$ ) was demonstrated.

To further characterize the antigens in RA synovial membrane, we used an additional rabbit anti-synthetic peptide antibody prepared against an adjacent region of the glycine-alaninerich region of EBNA-1 (peptide IR3-VI-0). This antibody reacts with purified EBNA-1 (Fig. 8, lane $B$ ) and with a 75,000-molwt band from an extract of EBV-transformed cells (Fig. 8, lane $C)$. Of importance, no band at $62,000 \mathrm{~mol}$ wt was noted in Fig. 8 , lane $C$. When this same cell extract was probed with MAb P135, both the 75,000 and 62,000-mol-wt antigens were present (Fig. 8, lane $A$ ). When extracts of RA synovial membrane were examined (Fig. 8, lane $D$ ) with this rabbit antipeptide antibody, no reactivity at either 75,000 or 62,000 was noted. These results

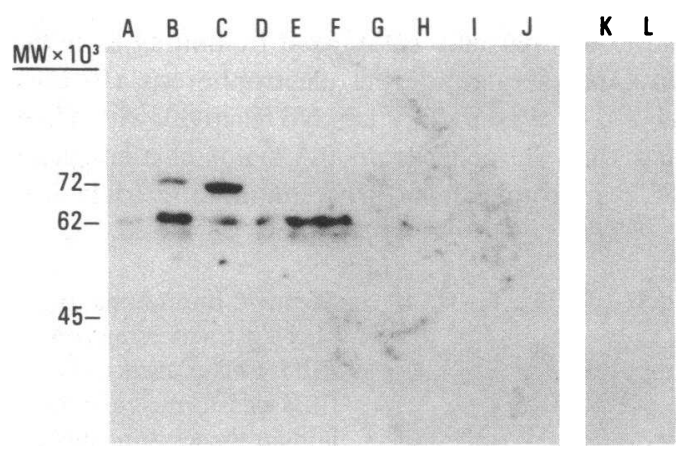

Figure 7. Reactivity of cell extracts with rabbit antibody directed against a glycine-alanine-containing synthetic peptide. Cell extracts from EBV-transformed cells or synovial membranes were examined with rabbit antisynthetic peptide IR-3-VI-2 (that contains glycine-alanine sequences) using ${ }^{125} \mathrm{I}$-staphylococcal protein $\mathrm{A}$ and immunoblotting. Lane $A$ : Extracts of EBV-negative cell line plus rabbit antipeptide IR3-VI-2. Lanes $B$ and $C$ : Cell extracts of EBV-transformed cell lines Wil-2 (lane $B$ ) and MH (lane $C$ ) plus rabbit antipeptide IR3-VI-2 antibody. Lanes $D-F$ : Cell extracts from RA synovium from three different patients plus rabbit antipeptide IR3-VI-2. Lanes $G-J$ : Cell extracts from two different normal and two different osteoarthritis synovial membranes plus rabbit antipeptide IR-3-VI-2 antibody. Lanes $I-K$ : Cell extracts from Wil-2 cells (lane $K$ ) and RA synovium (lane $L$ ) were probed with rabbit antipeptide IR3-VI-2 that had been pretreated with an excess of unlabeled peptide IR3-VI-2. 


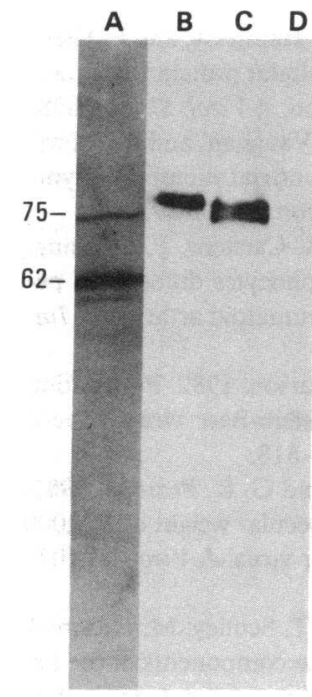

Figure 8. Reactivity of cell extracts of EBV-transformed cells and RA synovial membrane with anti-EBNA-1 antibodies. A cell extract of an EBV-transformed cell line was reacted with MAb P135 using immunoblotting methods as described above (lane $A$ ). Purified EBNA-1 antigen prepared by chromatofocusing (lane $B$ ) or cell extracts from an EBV-transformed $B$ cell line (lane $C$ ) were reacted with rabbit anti-EBNA peptide IR3-VI-0 antiserum. Cell extract from RA synovial membrane (lane $D$ ) was reacted with this rabbit antipeptide serum in a similar manner.

indicate that the 62,000-mol-wt protein found in RA synovial membrane lacks a peptide characteristic of EBNA-1 molecules.

\section{Discussion}

Despite an intensive search for infectious agents, the etiologic factors responsible for initiating and perpetuating RA remain largely unknown. While examining RA synovial tissues for evidence of EBV infection, we found that the synovial-lining cells were reactive with a MAb prepared against the EBNA-1 antigen. However, the antigen present in synovium differed from EBNA1 in several regards. First, it possessed a molecular weight of 62,000 that is lower than the $70,000-85,000 \mathrm{~mol}$ wt size of EBNA-1 (13). Second, it had a predominantly cytoplasmic location, in contrast to EBNA-1s intranuclear location. Finally, the RA synovial extract did not react with an antibody specific for a peptide (IR3-VI-0) found in EBNA-1. Taken together, these results suggest that RA synovial membrane contains a 62,000 mol-wt molecule that is distinct from EBNA-1 but that contains an epitope cross-reactive with EBNA-1. The structural basis for this cross-reactivity may reside in glycine-alanine-containing peptides, since a rabbit antibody against a particular synthetic peptide (IR3-VI-2) reacted with both EBNA-1 and with a 62,000 mol-wt synovial membrane protein. Since individuals with RA have strong antibody responses against this synthetic peptide of EBNA-1 (5), immunologic cross-reaction with a synovial membrane antigen could play a role in initiating or perpetuating the inflammatory process.

The finding of a cross-reactive antigen on synovial membrane tissue does not fully explain why only certain individuals develop RA. Virtually all adults are infected by EBV and normal synovial membranes contained the 62,000 -mol-wt antigen, although in smaller amounts. Therefore, additional factors must be involved in pathogenesis. It is likely that genetic factors such as the presence of histocompatibility antigen HLA-DR4 are important (32). The synovial-lining cells in RA show increased expression of HLA-DR antigen $(14,29,33,34)$, and previous studies have shown that these cells may "present" antigens to T cells (30). Thus, the immune system might be triggered to recognize the cross-reactive 62,000 -mol-wt protein when presented in the context of the HLA-DR4 histocompatibility antigen. Second, previous studies have shown that RA patients have a higher "load" of EBV-transformed lymphocytes in their circulation (6), and such infected cells may provide an increased antigenic stimulus to the RA patients. As a result, increased reactivity against the $62,000-$ mol-wt protein may develop. Finally, the cross-reactive 62,000 -mol-wt protein might not be sterically available in the intact synovial membrane. Thus, release of increased amounts of the 62,000 -mol-wt protein by proliferating synovial cells in RA patients or the degradation of the $62,000-\mathrm{mol}-\mathrm{wt}$ protein by synovial enzymes may present the immune system with an immunogenic stimulus.

The sharing of antigenic determinants between an infectious agent and a normal cellular protein has been termed "molecular mimicry." The pathogenetic potential of such shared antigenic epitopes has long been recognized in rheumatic fever $(35,36)$ and more recently in Chagas' disease (37), myasthenia gravis (38), and celiac sprue (39). Another possible example of molecular mimicry is the antigenic cross-reactivity of intermediate filaments of the vimentin-type and viral proteins from herpes simplex or measles virus (40-42). Although the cytoplasmic staining of synovial lining cells in situ and in vitro was suggestive of reaction with intermediary filaments such as vimentin, several lines of evidence argue against this possibility. First, the molecular weight of the protein reactive with MAb P135 (i.e., 62,000) is higher than the 52,000-mol-wt vimentin molecule (40). Second, the "cellular" 62,000 -mol-wt protein can be solubilized in the presence of only NP40 detergent, while intermediate filaments are insoluble under these conditions. Thus, we suspect that 62,000 -mol-wt antigen is a soluble protein that may associate with cytoskeletal elements and perhaps may influence cellular proliferation $(43,44)$. Also, it is possible that the previously reported presence of antibodies against intermediate filaments in RA sera (45) may in part be directed against the 62,000-mol-wt protein.

Silverman and Schumacher (46) found no increase in antiEBNA antibodies in the sera of RA patients early in the course of their disease. These workers used an immunofluorescence detection method that may yield different results than our enzyme-linked immunosorbent assay methods. For example, RA patients had elevated antibody titers only against certain glycinealanine-containing peptides (5). Antibody responses against particular antigenic regions of EBNA-1 might not be detectable in immunofluorescence assays. Also, preferential responses against particular antigenic regions of EBNA-1 may be responsible for increased anti-RANA (RA nuclear antigen) antibody titers in RA patients (47), since the RANA epitope appears to reside on the EBNA-1 molecule (31). Further studies on antibody and $T$ cell responses of RA patients early in the course of disease will be required to determine the potential importance of crossreactive antigens in pathogenesis.

In summary, we have found a 62,000 -mol-wt protein bearing an antigenic epitope cross-reactive with EBNA-1 in RA synovial membrane. The precise role of this cross-reactive antigen in the pathogenesis of RA remains unknown. However, antibodies to the 62,000-mol-wt protein are induced in parallel with antiEBNA antibodies in patients with infectious mononucleosis (13). Therefore, cross-reactions between EBNA-1 and the 62,000-molwt cellular protein can occur in vivo. Since RA patients have elevated levels of antibodies directed against synthetic peptides encoded by the IR-3 region of EBV (5), immune responses directed against a 62,000-mol-wt cross-reactive antigen may play a role in the initiation or perpetuation of their synovitis. 


\section{Acknowledgments}

We greatly appreciate the cooperation of our Rheumatology Department (Drs. E. Tan, C. Robinson, G. Williams, K. Hench, J. Curd, and F. Kozin), Orthopedics Department (Drs. C. Colwell, M. Hamer, R. Thorne, and P. Hirschman), Pathology Department (Drs. J. Robb, S. Nichols, and G. Bordin), and the operating room nurses for helping us to conduct these studies on their patients. We thank Drs. R. Nowinski (Genetic Systems, Seattle, WA), R. Gallo (National Institutes of Health, Bethesda, MD), and M. Oldstone (Scripps Clinic, La Jolla, CA) for their generous gifts of MAbs. We also appreciate the aliquots of rabbit antihepatitis $B$ antigen-associated peptide (Dr. A. Altman) and antihuman rheumatoid factor CDR3-associated peptide (Dr. A. Altman and Dr. D. Carson, of our institution). We particularly thank Drs. Dennis Carson, Sherman Fong, Constantine Tsoukas, Eng Tan, and Frank Kozin for their helpful discussions. We thank Ms. Darla Harlow, Sheri Kittle, and Shobha Ratnam for excellent technical assistance and the BCR Word Processing Center for typing this manuscript.

This research was supported by research grants AM33294, AM33983, CA25340, and CA39617 of the National Institutes of Health and a gift from the Kieckhefer Foundation.

\section{References}

1. Depper, J. M., and N. J. Zvaifler. 1981. Epstein-Barr virus. Its relationship to the pathogenesis of rheumatoid arthritis. Arthritis Rheum. 24:755-761.

2. Slaughter, L., D. A. Carson, F. C. Jensen, T. L. Holbrook, and J. H. Vaughan. 1978. In vitro effects of Epstein-Barr virus on peripheral blood mononuclear cells from patients with rheumatoid arthritis and normal subjects. J. Exp. Med. 148:1429-1434.

3. Alspaugh, M. A., and E. M. Tan. 1976. Serum antibody in rheumatoid arthritis reactive with a cell-associated antigen. Arthritis Rheum. 19:711-719.

4. Catalano, M. A., D. A. Carson, J. C. Niederman, P. Feorino, and J. H. Vaughan. 1980. Antibody to the rheumatoid arthritis nuclear antigen: its relationship to in vivo Epstein-Barr virus infection. J. Clin. Invest. 65:1238-1242.

5. Rhodes, G., D. A. Carson, J. Valbracht, R. Houghten, and J. H. Vaughan. 1985. Human immune responses to synthetic peptides from the Epstein-Barr nuclear antigen. J. Immunol. 134:211-216.

6. Tosato, G., A. D. Steinberg, R. Yarchoan, C. A. Heliman, S. E. Pike, V. DeSeau, and R. M. Blaese. 1984. Abnormally elevated frequency of Epstein-Barr virus-infected B cells in the blood of patients with rheumatoid arthritis. J. Clin. Invest. 73:1789-1795.

7. Depper, J. M., H. G. Bluestein, and N. J. Zvaifler. 1981. Impaired regulation of Epstein-Barr virus-induced lymphocyte proliferation in rheumatoid arthritis is due to a T cell defect. J. Immunol. 127:18991902.

8. Tosato, G., A. D. Steinberg, and R. M. Blaese. 1981. Defective EBV-specific suppressor T-cell function in rheumatoid arthritis. $N$. Engl. J. Med. 305:1238-1243.

9. Alspaugh, M. A., H. Shoji, and M. Nonoyama. 1983. A search for rheumatoid arthritis-associated nuclear antigen and Epstein-Barr virus specific antigens or genomes in tissues and cells from patients with rheumatoid arthritis. Arthritis Rheum. 26:712-720.

10. Yates, J., N. Warren, D. Reisman, and B. Sugden. 1984. A cisacting element from the Epstein-Barr viral genome that permits stable replication of recombinant plasmids in latently infected cells. Proc. Natl. Acad. Sci. USA. 81:3806-3810.

11. Hennessy, K., and E. Kieff. 1983. One of two Epstein-Barr virus nuclear antigens contains a glycine-alanine copolymer domain. Proc. Natl. Acad. Sci. USA. 80:5665-5669.

12. Heller, M., A. Henderson, and E. Kieff. 1982. A repeat sequence in Epstein-Barr virus DNA is related to interspersed repeated cell DNAs which are at specific sites on human chromosomes. Proc. Natl. Acad. Sci. USA. 79:5916-5920.
13. Luka, J., T. Kreofsky, G. R. Pearson, K. Hennessy, and E. Kieff. 1984. Identification and characterization of a cellular protein that crossreacts with the Epstein-Barr virus nuclear antigen. J. Virol. 52:833-838.

14. Young, C. L., T. C. Adamson III, J. H. Vaughan, and R. I. Fox. 1984. Immunohistologic characterization of synovial membrane lymphocytes in rheumatoid arthritis. Arthritis Rheum. 27:32-39.

15. Fox, R. I., S. Fong, N. Sabharwal, S. A. Carstens, P. C. Kung, and J. H. Vaughan. 1982. Synovial fluid lymphocytes differ from peripheral blood lymphocytes in patients with rheumatoid arthritis. J. Immunol. 128:351-354.

16. Qualtiere, L. F., R. Chase, and G. R. Pearson. 1982. Purification and biologic characterization of a major Epstein-Barr virus-induced membrane glycoprotein. J. Immunol. 129:814-818.

17. Vroman, B., J. Luka, M. Rodriguez, and G. R. Pearson. 1985. Characterization of a major protein with a molecular weight of 160,000 associated with the viral capsid of Epstein-Barr virus. J. Virol. 53:107113.

18. Pearson, G. R., B. Vroman, B. Chase, T. Sculley, M. Hummel, and E. Kieff. 1983. Identification of polypeptide components of the Epstein-Barr virus early antigen complex with monoclonal antibodies. J. Virol. 47:193-201.

19. Goldstein, L. C., J. McDougall, R. Hackman, J. D. Meyers, E. D. Thomas, and R. C. Nowinski. 1982. Monoclonal antibodies to cytomegalovirus: rapid identification of clinical isolates and preliminary use in diagnosis of cytomegalovirus pneumonia. Infect. Immun. 38:273281.

20. Goldstein, L. C., L. Corey, J. McDougall, E. Tolentinto, and R. Nowinski. 1983. Monoclonal antibodies to herpes simplex viruses: use of antigenic typing and rapid diagnosis. J. Infect. Dis. 147:829-837.

21. Robert-Guroff, M., F. W. Ruscetti, L. E. Posner, B. J. Poiesz, and R. C. Gallo. 1981. Detection of the human T cell lymphoma virus p19 in cells of some patients with cutaneous $T$ cell lymphoma and leukemia using a monoclonal antibody. J. Exp. Med. 154:1957-1964.

22. Fox, R. I., L. Thompson, and J. Huddlestone. 1981. T-gamma cells express T lymphocyte associated antigens. J. Immunol. 126:20622065.

23. Reinherz, E., L. Moretta, M. Roper, J. Breard, I. Mingari, M. Cooper, and S. Schlossman. 1980. Human T lymphocyte subpopulations defined by Fc receptors and monoclonal antibodies: a comparison. J. Exp. Med. 151:969-980.

24. Kay, D., and D. Horwitz. 1980. Evidence by reactivity with hybridoma antibodies for a probable myeloid origin of peripheral blood cells active in natural cytotoxicity and antibody-dependent cell-mediated cytotoxicity. J. Clin. Invest. 66:847-856.

25. Rhodes, G., R. Houghten, J. P. Taulane, D. A. Carson, and J. H. Vaughan. 1984. The immune response to Epstein-Barr nuclear antigen: conformational and structural features of antibody to synthetic peptides. Mol. Immunol. 21:1047-1054.

26. Sportsman, J. R., and J. H. Elder. 1984. A microanalytical protein assay using laser densitometry. Anal. Biochem. 139:298-300.

27. Johnson, D. A., J. W. Gautsch, J. R. Sportsman, and J. H. Elder. 1983. Improved technique utilizing non-fat dried milk for analysis of proteins and nucleic acids transferred to nitrocellulose. Gene. Anal. Tech. 1:3-7.

28. Janossy, G., G. Panayi, O. Duke, M. Bofill, L. W. Poulter, and G. Goldstein. 1981. Rheumatoid arthritis: a disease of T-lymphocyte/ macrophage immunoregulation. Lancet. ii:839-841.

29. Klareskog, L., U. Forsum, D. Kabelitz, L. Ploen, C. Sundstrom, K. Nilsson, A. Wigren, and H. Wigzell. 1982. Immune functions of human synovial cells. Phenotypic and T-cell regulatory properties of macrophage-like cells that express HLA-DR. Arthritis Rheum. 25:488501.

30. Konttinen, Y., S. Reitamo, A. Ranki, P. Hayry, U. Kankaanapaa, and O. Wegelius. 1981. Characterization of the immunocompetent cells of rheumatoid synovium from tissue sections and eluates. Arthritis Rheum. 24:71-79.

31. Billings, P., S. Hoch, P. White, D. Carson, and J. Vaughan. 1983. Antibodies to the Epstein-Barr virus nuclear antigen and to the rheu- 
matoid arthritis nuclear antigen identify the same polypeptide. Proc. Natl. Acad. Sci. USA. 80:7104-7108.

32. Stastny, P. 1978. Association of B-cell alloantigen DRW and with rheumatoid arthritis. N. Engl. J. Med. 298:869-874.

33. Klareskog, L., U. Forsum, M. Tjernlund, D. Kabelitz, and A Wigren. 1981. Appearance of anti-HLA-DR-reactive cells in normal and rheumatoid synovial tissue. Scand. J. Immunol. 14:183-192.

34. Winchester, R. J., and G. R. Burmester. 1981. Demonstration of la antigens on certain dendritic cells and on a novel elongate cell found in human synovial tissue. Scand. J. Immunol. 14:439-444.

35. Van de Rijn, I., J. B. Zabriskie, and M. McCarty. 1977. Group A streptococcal antigens cross-reactive with myocardium. J. Exp. Med. 146:579-596.

36. Dale, J. B., and E. H. Beachey. 1985. Multiple, heart-cross-reactive epitopes of streptococcal M proteins. J. Exp. Med. 161:113-122.

37. Wood, J. N., L. Hudson, T. M. Jessell, and M. Yamamoto. 1982. A monoclonal antibody defining antigenic determinants on subpopulations of mammalian neurones and Trypanosoma cruzi parasites. Nature (Lond.). 296:34-37.

38. Stefansson, K., M. E. Dieperink, D. P. Richman, C. M. Gomez, and L. S. Marton. 1985. Sharing of antigenic determinants between the nicotinic acetylcholine receptor and proteins in escherichia coli, proteus vulgaris, and klebsiella pneumoniae: possible role in the pathogenesis of myasthenia gravis. $N$. Engl. J. Med. 312:221-225.

39. Kagnoff, M. F., R. K. Austin, J. J. Hubert, J. E. Bernardin, and D. D. Kasarda. 1984. Possible role for a human adenovirus in the pathogenesis of celiac disease. J. Exp. Med. 160:1544-1557.
40. Fujinami, R. S., M. B. A. Oldstone, Z. Wroblewska, M. E. Frankel, and $H$. Koprowski. 1983. Molecular mimicry in virus infection: crossreaction of measles virus phosphoprotein or of herpes simplex virus protein with human intermediate filaments. Proc. Natl. Acad. Sci. USA. 80: 2346-2350.

41. Toh, B. H., A. Yildiz, J. Sotelo, O. Osung, E. J. Holborow, F. Kanakoudi, and J. V. Small. 1979. Viral infections and IgM autoantibodies to cytoplasmic intermediate filaments. Clin. Exp. Immunol. 37: 76-82.

42. Linder, E., P. Kurki, and L. C. Andersson. 1979. Autoantibody to 'intermediate filaments' in infectious mononucleosis. Clin. Immunol. Immunopathol. 14:411-417.

43. Lazarides, E. 1982. Intermediate filaments a chemically heterogeneous, developmentally regulated class of protein. Ann. Res. Biochem. 51:219-227.

44. Burgess, A. 1985. Growth factors and oncogenes. Immunol. To day. 6:107-110.

45. Osung, O. A., M. Chandra, and E. J. Holborow. 1982. Antibody to intermediate filaments of the cytoskeleton in rheumatoid arthritis. Ann. Rheum. Dis. 41:69-73.

46. Silverman, S. L., and R. Schumacher. 1981. Antibodies to EpsteinBarr viral antigens in early rheumatoid arthritis. Arthritis Rheum. 24: 1465-1468.

47. Ferral, P., C. Aitcheson, G. Pearson, and E. M. Tan. 1981. Seroepidemiologic study of relationships between Epstein-Barr virus and rheumatoid arthritis. J. Clin. Invest. 67:681-687. 